\title{
pHyloGASTRO $^{\circledR}$ IN THE TREATMENT OF EQUINE GASTRIC ULCER LESIONS
}

Bonelli Francesca ${ }^{1}$, Busechian Sara ${ }^{2}$, Meucci Valentina ${ }^{1}$, Caporrino Giusy ${ }^{3}$, Briganti Angela $^{2}$, Rueca Fabrizio ${ }^{2}$, Zappulla Francesco ${ }^{2}$, Ferini Ersilia ${ }^{4}$, Ghiandai Luana ${ }^{4}$, Sgorbini Micaela ${ }^{1}$.

${ }^{1}$ Department of Veterinary Sciences, via Livornese snc, 56122 San Piero a Grado (PI), Italy.

${ }^{2}$ Department of Clinical Sciences, University of Perugia, Perugia, Italy.

${ }^{3}$ Equine practitioner, Pisa.

${ }^{4}$ Union B.I.O. srl, Italy.

Corresponding author

Micaela Sgorbini

Department of Veterinary Sciences

Via Livornese snc

56122, San Piero a Grado, Pisa, Italy

$+390502210117$

micaela.sgorbini@unipi.it 


\section{Highlights}

21 1. Equine Gastric Ulcer Syndrome (EGUS) is the most common disease of the equine 22 stomach with a high prevalence.

2. Nutraceutical compounds have been shown to have a positive effect on preventing or healing naturally occurring gastric ulcers.

3. pHyloGASTRO ${ }^{\circledR}$ is a herbal feed composed of medical herbs that act on restoring the 26 acid-base balance.

27 4. pHyloGASTRO ${ }^{\circledR}$ seems to be an effective feed additive for the improvement of gastric lesions.

5. We believe that the 6 -week treatment period, recommended by the manufacture, is too short, since often gastric mucosal lesions did not completely heal in our treated group. 


\section{Abstract}

Equine Gastric Ulcer Syndrome (EGUS) is the most common disease of the equine stomach with high prevalence of both squamous and glandular disease reported in various populations.

The aim of this study was to evaluate the effectiveness of a phytotherapic compound (pHhyloGASTRO ${ }^{\circledR}$ ) in the therapy of EGUS.

Materials and methods. The study was performed as a randomised double-blinded single centre study. The study population was composed of 19 equids which were submitted to gastroscopy before and after a six-week treatment with feed additive (10/19) (pHyloGASTRO ${ }^{\circledR},{ }^{4}$ Union B.I.O. srl, Italy) or a placebo (9/19). Severity grade was evaluated on a scale from 0-4. The variables of interest were gastric lesion score and improvement grade. Changes and comparisons of variables were performed by contingency table analyses. P level of significance was set at 0.05 in all analyses.

Results. In terms of gastric lesion scores, the treated group improved significantly compared to the placebo group.

Discussion and conclusions. pHyloGASTRO ${ }^{\circledR}$ seems to be effective in the treatment of EGUS. Further studies are needed to verify whether prolonged administration of pHyloGASTRO ${ }^{\circledR}$ could be more effective in completely healing gastric lesions.

\section{Key words}

Equids, EGUS, treatment, nutraceutical compounds, pHyloGASTRO ${ }^{\circledR}$ 


\section{Introduction}

Gastric ulceration is the most common disease of the equine stomach with a high prevalence of both squamous and glandular disease reported in various populations [1-3]. The term Equine Gastric Ulcer Syndrome (EGUS) was first adopted by the EGUS Council in 1999 and includes a complex of pathological conditions characterized by the presence of ulcers in the terminal portion of the oesophagus, in the proximal (squamous) and distal (glandular) parts of the stomach, and in the proximal part of the duodenum of equids [4]. Recently various authors [5-7] and the European College of Equine Internal Medicine (ECEIM) Consensus Statement [8] have provided a new nomenclature of EGUS and proposed updated guidelines regarding pathophysiology, diagnosis, and treatment $[5,8]$.

Many drugs have been investigated and are available for the treatment and management of EGUS [8-11]. The proton pump inhibitor omeprazole has been found to be very efficient in both treating and preventing gastric ulcers in horses [8]. Other drugs such as histamine 2 antagonists or gastric mucosal protectors have shown less efficacy than omeprazole in the treatment of EGUS $[8,11,12]$.

Along with pharmacological therapies, nutraceutical compounds appear to have a positive effect on preventing or healing naturally occurring gastric ulcers [13-20]. Thus, interest in more natural products has been growing. The purpose of this study was to evaluate the effect of the feed additive pHyloGASTRO ${ }^{\circledR}$ (Union B.I.O. srl, Italy) on the treatment of spontaneously occurring gastric ulcers of the squamous mucosa in a population of equids.

\section{Methods}

2.1 Materials

The study population was composed of 19 equids (ten Standardbred trotting horses and nine Amiata donkeys). The equids were equal regarding distribution of gender and breed. None of the animals showed clinical signs of EGUS, were athletes and were used for reproduction. Inclusion criteria: 1) all the equids were affected by gastric ulcers at gastroscopy; no changes in the feeding and environment during the study period were made.

\subsection{Study design}

The study was performed as a randomised double-blinded single centre study and the protocol was approved by the Ethical Committee of the University of Pisa [no. 9069/2014]. Group allocation and blinding: once enrolled into the study, horses were randomly allocated to a dose group by pulling their names out of a hat. One investigator (F.B.) was 
responsible for randomisation while another investigator (S.B.) remained blinded to the group allocation until scoring was completed and recorded.

Ulcers were diagnosed by gastroscopy performed under sedation after 12 hours of fasting and 4 hours of water deprivation as reported in the literature [21]. Severity grade was evaluated on a scale from 0-4 as proposed by others [4]. Gastroscopy was always performed by the same operator (S.B.), as indicated by others [22]. For the examination, a $300 \mathrm{~cm}$ scope (Karl Storz, Germany) and a portable processor (Gastropack, Karl Storz, Germany) were used. The images were stored on a DVD recorder. The stomach was insufflated with air through an air-flow system attached to the biopsy channel of the scope until the internal stomach folds appeared flattened. Feed material adhering to the nonglandular mucosa was flushed away with sterile water in order to visualize the entire nonglandular portion of the stomach, including the greater curvature, the lesser curvature, and the dorsal fundus. The number and degree of ulcers were recorded in accordance with the Equine Gastric Ulcer Council (EGUC) recommendations [4].

Equids were divided in two groups: the "placebo group" was composed of 9/19 animals (median age 10 years); the "treated group" was composed of 10/19 animals (median age 8 years). The two treatment groups were clinically equal regarding distribution of gender and breed. The "treated group" was treated with pHyloGASTRO ${ }^{\circledR}$ (Union B.I.O. srl, Italy) at a dose of $60 \mathrm{ml}$ per equid BID PO for 6 weeks, while the "placebo group" was treated BID with a similar-looking same-volume placebo for 6 weeks. Both pHyloGASTRO ${ }^{\circledR}$ and placebo were administered using a feeding device. The administration was always performed by the same operator (C.G.). pHyloGASTRO ${ }^{\circledR}$ is composed of medical herbs (Althaea officinalis, Aloe barbadensis, Hoedeum vulgar, Malva sylvestris, Glycyrrhiza glabra, Echinacea angustifolia, calendula officinalis, Clay ventilated) powered by Matrix $U B^{\circledR}$ (the aqueous extract of Olea europaea, a phyto-active enhancer). The medical herbs previously reported showed antinflammatory, cytoprotective, antioxidant, mucus healing, and acid-base balance restoring activities (table 1) [23-38]. A clinical examination was carried out daily for each animal to monitor gastro-intestinal side effect. All the equids were submitted to a gastroscopy after the 6-week treatment.

2.3 Statistical analysis

The variables of interest were gastric lesion score and improvement grade. Changes and comparisons on variables were performed by contingency table analyses. Significance was set at 0.05 in all analyses. All the analyses were performed using a GraphPad Prism 6.0 (USA). 


\section{Results}

All the equids in the study were affected by gastric ulcers in the non-glandular mucosa (Equine Squamous Gastric Disease, ESGD) [5,8]. No health problems or side effects (diarrhoea, stipsis, disorexia or anorexia, colic) related to treatment with pHyloGASTRO ${ }^{\circledR}$ were observed during the all study period. The feed additive was readily accepted by all the pHyloGASTRO ${ }^{\circledR}$-treated horses in the same manner as the placebo. Before treatment, the "treated group" equids showed 2/10 grade 1, 6/10 grade 2, 1/10 grade 3, while no equids showed grade 4; the "placebo group" equids showed 3/9 grade 1, $3 / 9$ grade 2, 3/9 grade 3, while no equids showed grade 4 . The pre-treatment distribution of gastric lesion scores was not significantly different between the two groups. After 6 weeks of treatment, the "treated group" showed 2/10 equids with grade 0, 7/10 with grade 1, 1/10 with grade 3, while no animals showed grades 2 and 4; the "placebo group" showed 2/9 with grade 0, 2/9 with grade 1, 3/9 with grade 2, and 2/9 with grade 3 , while no animals showed grade 4. Outcomes for both "placebo" and "treated" groups are reported in table 2 .

The "treated group" improved significantly compared to the "placebo group" $(p=0.04)$. Concerning the improvement score of the gastric lesions, equids treated with pHyloGASTRO $^{\circledast}$ showed a significantly $(p=0.0001)$ higher improvement than equids treated with the placebo (Table 3).

No differences were found between the two groups considering complete healing of gastric lesions vs improvement.

\section{Discussion}

EGUS is a complex disease, which for nearly 30 years has been recognized as a highly prevalent condition both in training and at rest horses [5,8,11]. A new nomenclature of EGUS along with updated guidelines regarding pathophysiology, diagnosis, and treatment have recently been proposed [5-8]. In particular, the European College of Equine Internal Medicine (ECEIM) committee recognizes that the terminology for EGUS needed clarification and proposes the nomenclature of Equine Squamous Gastric Disease (ESGD) amd Equine Glandular Gastric Disease (EGGD) [15].

The pharmacology products most commonly used for the treatment of gastric ulcers in horses focus on blocking gastric acid secretion and increasing stomach $\mathrm{pH}$, which creates a permissive environment for physiological ulcer healing [8,10-11]. However, the research 
156 for methods to treat or prevent gastric ulcers effectively without requiring the continued administration of costly pharmaceutical agents together with issues regarding withdrawal times or side effects is a new trend not only in human medicine, but also in veterinary medicine.

In order to meet this growing need for more natural products, this study aimed to evaluate the effectiveness of pHyloGASTRO ${ }^{\circledR}$ in the treatment of EGUS in adult equids. Our results showed an easy administration and ingestion of pHyloGASTRO ${ }^{\circledR}$ by the treated horses, with no health problems or side effects related to the treatment. A total of $44.4 \%$ of the "placebo" horses and $80 \%$ of the "treated" horses showed an improvement or a complete healing of the ulcers.

The improvement in the degree of ulceration score in the "placebo" group was similar compared to previous studies [17]. An improvement in placebo-treated patients has been reported in humans [39-41] and some studies have been published in veterinary medicine [42-43].

Also the improvement in the degree of ulcerations in the "treated" group is in line with a previous study [17], which investigated the effect of a nutraceutical compound and found an improvement of $77.8 \%$ of the horses treated.

Comparing the two groups, statistical calculations revealed a significant reduction in gastric mucosal lesions in the "treated" horses compared to the "placebo" group after six weeks of administration of the nutraceutical feed. This is in line with findings reported in previous papers where different nutraceutical compounds were tested [14-15,17,19-20]. Concerning the gastric lesion scores, equids treated with pHyloGASTRO ${ }^{\circledR}$ improved more significantly $(p=0.0001)$ than equids treated with the placebo. Our results are in line findings reported in the literature [17,19-20].

\section{Conclusions}

pHyloGASTRO $^{\circledR}$ seems to be an effective feed additive for the improvement of gastric lesions. However, the treatment period of six weeks, recommended by the manufacture, seems too short, since the gastric mucosal lesions had often not completely healed in the treated group. Thus, further studies are needed to verify whether a prolonged administration of pHyloGASTRO ${ }^{\circledR}$ could be more effective in obtaining a complete healing of gastric lesions. A limitation of the study could be the lack of a group treated only with the 
188 Matrice $U B^{\circledR}$ solution. The addition of this group could lead to understanding whether the 189 improvement to EGUS lesions was due to medical herbs, to Matrice $U B^{\circledR}$ or both. 


\section{REFERENCES}

[1] Luthersson N, Nielsen KH, Harris P, Parkin TDH. Risk factors associated with equine gastric ulceration syndrome (EGUS) in 201 horses in Denmark. Equine vet $\mathrm{J}$ 2009;41:625-30.

[2] Tamzali Y, Marguet C, Priymenko N, Lyazrhi F. Prevalence of gastric ulcer syndrome in high-level endurance horses. Equine vet J 2011;43:141-4.

[3] Habershon-Butcher JL, Hallowell GD, Bowen IM, Sykes BW. Prevalence and risk factors for ulceration of the gastric glandular mucosa in Thoroughbred racehorses in training in the UK and Australia. J Vet Intern Med 2012;26:731.

[4] EGUC (Equine Gastric Ulcer Council). Recommendations for the diagnosis and treatment of equine gastric ulcer syndrome (EGUS), Equine vet Educ 1999;11(5):262-272.

[5] Sykes BW, Jokisalo JM (2014a). Rethinking equine gastric ulcer syndrome: Part 1 Terminology, clinical signs and diagnosis. Equine vet Educ 26(10): 543-7.

[6] Sykes BW, Jokisalo JM. Rethinking equine gastric ulcer syndrome: Part 2 - Equine squamous gastric ulcer syndrome (ESGUS). Equine vet Educ 2015;27(5): 264-8.a

[7] Sykes BW, Jokisalo JM. Rethinking equine gastric ulcer syndrome: Part 3 - Equine glandular gastric ulcer syndrome (EGGUS). Equine vet Educ 2015;27(7):372-5.b

[8] Sykes BW, Hewetson M, Hepburn RJ, Luthersson N, Tamzali Y. ECEIM Consensus Statement- Equine Gastric Ulcer Syndrome in Adult Horses: J Vet Intern Med 2015;29:1288-99.

[9] MacAllister CG. A review of medical treatment for peptic ulcer disease. Equine vet $\mathrm{J}$ Suppl1999;29:45-9.

[10] Buchanan BR, Andrews FM. Treatment and prevention of equine gastric ulcer syndrome. Vet Clin North Am Equine Pract 2004;19(3):575-97.

[11] Videla R, Andrews FM. New perspectives in equine gastric ulcer syndrome. Vet Clin North Am Equine Pract 2009;25(2):283-301.

[12] Andrews F, Bernard W, Byars D, Cohen N, Divers T, MacAllister C. Reccommendations for the diagnosis and treatment of equine gastric ulcer syndrome (EGUS). Equine vet Educ 1999;11:262-72.

[13] Clark CK, Merritt AM, Burrow JA, Steible CK. Effect of aluminium 
hydroxide/magnesium hydroxide antacid and bismuth subsalicylate on gastric $\mathrm{pH}$ in horses. J Am Vet Med Assoc 1996;208:1687-91.

[14] Venner M, Lauffs S, Deegen E. Treatment of gastric lesions in horses with pectin-lecithin complex. Equine Vet J Suppl 1999;29:91-6.

[15] Murray MJ, Grady TC. The effect of a pectin-lecithin complex on prevention of gastric mucosal lesions induced by feed deprivation in ponies. Equine vet $\mathrm{J}$ 2002;34(2):195-8.

[16] Ferrucci F, Zucca E, Croci C, Di Fabio V, Ferro E. Treatment of gastric ulceration in 10 standardbred racehorses with a pectin-lecithin complex. Vet Rec 2003;52(22):679-81.

[17] Hellings IR, Larsen S. ImproWin ${ }^{\circledR}$ in the treatment of gastric ulceration of the squamous mucosa in trotting racehorses. Acta Vet Scand 2004;56(13):2-7.

[18] Huff NK, Auer AD, Garza F, Keowen ML, Kearney MT, McMullin RB, Andrews FM. Effect of sea buckthorn berries and pulp in a liquid emulsion on gastric ulcer scores and gastric juice pH in horses. J Vet Int Med 2012;26:1186-91.

[19] Woodward MC, Huff NK, Garza FJr, Keowen ML, Kearney MT, Frank M, et al. (2014). Effect of pectin, lecithin, and antacid feed supplements (Egusin $®$ ) on gastric ulcer scores, gastric fluid $\mathrm{pH}$ and blood gas values in horses. BMC Vet Res 2014;10(Suppl 1)S4:2-8.

[20] Sykes BW, Sykes KM, Hallowell GD. Efficacy of a combination of Apolectol ${ }^{\circledR}$, live yeast (CNCM I-1077) and magnesium hydroxide in the management of Equine Gastric Ulcer Syndrome in thoroughbred racehorses: A randomised, blinded, placebo controlled clinical trial. J Equine Vet Sci 2014b;34:1274-8.

[21] Murray MJ. Endoscopy. In: Mair T, Divers T, Ducharme N, editors. Manual of Gastroenterology, UK: WB Saunders, Elsevier; 2002, p. 21-6.

[22] Bain FT, Petrizzi L, Valbonetti L, Muttini A. Gastroscopy and duodenoscopy. In Slovis NM editor. Atlas of equine endoscopy. St. Lois, Missouri: Mosby-Elsevier; 2004, p. 147-68.

[23] Eamlamnan K, Patumraj S, Visedopas, N, Thong-Ngam D. Effects of Aloe vera ans sucralfate on gastric microcirculatory changes, cytokine levels and gastric ulcer healing in rats. World J Gastroenterol 2006;12(3):2034-9. 
[24] Hage-Sleiman R, Mroueh M, Daher CF. Pharmacological evaluation of aqueous extract of Althaea officinalis flower grown in Lebanon. Pharmaceutical Biol 2011;49(3):327-33.

[25] Al-Dalain S, El-Kutry S, Ibrahim HS. Inhibitory effect of aqueous extracts of barley and fenugreek on ulcer induction in rats. World Appl Sci J 2008;5(3):332-9.

[26] Della Greca M, Cutillo F, D'Abrosca B, Fiorentino A, Pacifico S, Zarrelli A. Antioxidant and radical scavenging properties of Malva sylvestris. Nat Prod Commun 2009;4(7):893-6.

[27] Sleiman NH, Daher CF. Malva sylvestris water extract: a potential antiinflammatory and anti-ulcerogenic remedy. Planta Med 2009;75:1010.

[28] Gasparetto JC, Ferreira Martins CA, Hayashi SS, Otuky MF, Pontarolo R. Ethnobotanical and scientific aspects of Malva sylvestris L: a millennial herbal medicine. JPP 2011;64:172-89.

[29] Hollanders D, Green G, Woolf IL, Boyes BE, Wilson RY, Cowley DJ, et al. Prophylaxis with deglycyrrhizinised liquorice in patients with healed gastric ulcer. $\mathrm{Br}$ Med J 1978;1:148.

[30] European Medicines Agency. Assessment report on Glycyrrhiza glabra L. and/or Glycyrrhiza inflata Bat. and/or Glycyrrhiza uralensis Fisch., radix. Committee on Herbal Medicinal Products (HMPC), Final - 12 March 2013. http://www.ema.europa.eu/docs/en_GB/document_library/Herbal_HMPC_assessm ent_report/2012/08/WC500131285.pdf

[31] Asl MN, Hosseinzadeh H. Review of pharmacological effects of Glycyrrhiza sp. and its bioactive compounds. Phytother Res 2008;22:709-24.

[32] Sharkawi SM, El-Sherbiny GA, Ain-Shoka AA, El-Sayed ME. Prophylactic role of Echinacea, Green Tea and Boswellia extracts in pyloric ligation-induced gastric ulcer in rats. Br J Pharmacol Toxicol 2012;3(5):197-204.

[33] Dizaye K, Ali RH. Gastroprotective effects of calendula officinalis extract. The Third International Conference for Medical Sciences, Erbil, Iraq, 24-26 October 2012;pp.88-98.

[34] Cervini-Silva J, Nieto-Camacho A, Ramirez-Apan MT, Gomez-Vidales V, Palacios E, Montoya A, et al. Anti-inflammatory, anti-bacterial, and cytotoxic activity 
of fibrous clays. Colloids Surf B Biointerfaces 2015;129:1-6.

[35] Bitler CM, Viale TM, Damaj B, Crea R (2005) Hydrolyzed olive vegetation water in mice has anti-inflammatory activity. J Nutr 2005;135(6):1475-9.

[36] Dekanski D, Janicijevic-Hudomal S, Ristic S, Mitrovic D. Attenuation of cold restraint stress-induced gastric lesions by an olive leaf extract. Gen Physiol Biophys 2009;28:135-42.a

[37] Dekanski D, Ristić S, Mitrović DM. Antioxidant effect of dry olive (Olea europaea L.) leaf extract on ethanol-induced gastric lesions in rats. Mediterranean J Nutr Metabol 2009;2(3): 205-11.b

[38] Cumaoglu A, Ari N, Kartal M, Karasu Q. Polyphenolic extracts from Olea europea $L$. protect against cytokine-induced $p$-cell damage through maintenance of redox homeostasis. Rejuvenation Res 2011;14(3):325-4.

[39] Del Re AC, Maisel N, Blodgett JC, Finney JW. Placebo Group Improvement in Trials of Pharmacotherapies for Alcohol Use Disorders: A Multivariate MetaAnalysis Examining Change Over Time. J Clin Psychopharmacol 2013;33(5):64957.

[40] Oken BS. Placebo effects: clinical aspects and neurobiology. J Clin Psychopharmacol 2013; 131(11):2812-23.

[41] Voudouris, NJ, Peck, CL, Coleman, G. Conditioned placebo responses. J Pers Soc Psychol 1985;48:47-53.

[42] McMillan, FD. The Placebo Effect in Animals. J Am Vet Med Assoc 1999;215(7):992-9.

[43] Wilson, DV, Lankenau C, Berney, CE, Peroni, DL, Mullineaux DR, Robinson NE C. The effects of a single acupuncture treatment in horses with severe recurrent airway obstruction. Equine vet J 2004;36(6):489-94. 


\begin{tabular}{|l|l|l|}
\hline \multicolumn{1}{|c|}{ Medical herbs } & \multicolumn{1}{c|}{ Mechanism of action } & Literature \\
\hline Althaea officinalis & Antinflammatory, cytoprotective & {$[23,24]$} \\
\hline Aloe barbadensis & Antinflammatory, cytoprotective, mucus healing & {$[23]$} \\
\hline Hordeum vulgare & Cytoprotective, mucus healing, acid-base restoring & {$[25]$} \\
\hline Malva sylvestris & Anti ulcerogenic activity & {$[26-28]$} \\
\hline Glycyrrhiza glabra & Gastric healing & {$[29-31]$} \\
\hline Echinacea angustifolia & Oxidant-antioxidant balance & {$[32]$} \\
\hline Calendula officinalis & Antiulcer, antinflammatory effect & {$[33]$} \\
\hline Clay ventilated & Ulcer healing & {$[34]$} \\
\hline Olea europea & Gastroprotective agent, antioxidant activity & {$[35-38]$} \\
\hline
\end{tabular}

Table 1 - Mechanism of action of medical herbs that are compounds of pHyloGASTRO $^{\circledR}$ (Union B.I.O. srl, Italy). 


\begin{tabular}{|c|c|}
\hline \multicolumn{2}{|c|}{ PLACEBO GROUP } \\
\hline Pre-treatment lesion score & Post-treatment lesion score \\
\hline 3 & 3 \\
\hline 1 & 0 \\
\hline 2 & 2 \\
\hline 3 & 3 \\
\hline 1 & 0 \\
\hline 1 & 1 \\
\hline 2 & 1 \\
\hline 3 & 2 \\
\hline 2 & 2 \\
\hline \multicolumn{2}{|c|}{ TREATED GROUP } \\
\hline Pre-treatment lesion score & Post-treatment lesion score \\
\hline 3 & 3 \\
\hline 1 & 1 \\
\hline 3 & 1 \\
\hline 2 & 1 \\
\hline 1 & 0 \\
\hline 2 & 0 \\
\hline 2 & 1 \\
\hline 2 & 1 \\
\hline 2 & 1 \\
\hline 2 & 1 \\
\hline
\end{tabular}

325 Table 2 - Pre and post treatment lesion score outcome in "placebo" and "treated" groups. 326 
328 Table 3 - Change in gastric lesion scores before and after 6-week period between 329 "control" and "treated" groups. 